OPEN ACCESS

Edited by:

Yan Zeng,

Institute of Zoology, Chinese

Academy of Sciences, China

Reviewed by:

Francois Bastardie,

Technical University of Denmark,

Denmark

Ray Hilborn,

University of Washington,

United States

*Correspondence:

Jake Rice

jake.rice@dfo-mpo.gc.ca

Specialty section:

This article was submitted to

Conservation and Restoration

Ecology,

a section of the journa

Frontiers in Ecology and Evolution

Received: 31 December 2020

Accepted: 03 March 2021

Published: 30 March 2021

Citation:

Rice J (2021) Equity -

the Bottleneck and the Opportunity.

Front. Ecol. Evol. 9:648550

doi: 10.3389/fevo.2021.648550

\section{Equity - the Bottleneck and the Opportunity}

\author{
Jake Rice \\ Fisheries and Oceans Canada, Ottawa, ON, Canada
}

There is a widespread tendency for diverse uses of Nature, on scales from small and local to very large, to become unsustainable. Once unsustainable, bringing a use back to sustainability and keeping it sustainable then takes substantial effort and tools appropriate to the context of the use. This Perspective first asks why is the tendency for unsustainability so pervasive, when it is an outcome that no user group has adopted as an objective, and ways to keep uses sustainable are known. I argue and present evidence that the common factor underlying the pervasiveness of unsustainable uses of Nature is inequity in the distribution of the benefits created from those uses, with both the wealthy "winners" of the distributional inequities and those disadvantaged and in poverty driving uses toward increasing unsustainability in ways that depend on the nature of the inequities. Unless the inequity of distribution of benefits from uses of Nature is addressed as an issue in its own right, there are few or no pathways to medium or long-term sustainable use. However, if inequity is addressed broadly and effectively, many pathways are available and societies can select the pathways appropriate to their cultural and ecological contexts.

Keywords: inequity, sustainable use, scale, uses of Nature, transformational change, drivers of unsustainability

\section{INTRODUCTION}

The thesis of this Perspective is straightforward. It is that as inequity in the distribution of benefits from any use of Nature increases, the likelihood that the associated use can be made and kept sustainable both decrease correspondingly, and at an accelerating rate as the degree of inequity grows. After roles on many regional and national assessment teams of various sorts for four decades $^{1}$, I have had opportunities to examine the prominence of unsustainable uses of Nature from many different perspectives. Several patterns have emerged:

- Sustainable uses of Nature and its components are feasible, and they have been achieved on scales from small to very large (Hilborn, 2019; Hilborn et al., 2020).

- Being feasible does not mean sustainability of the uses are simple to achieve, and having been achieved does not mean the uses then have been easy to keep sustainable.

\footnotetext{
${ }^{1}$ E.g. co-chairing one of the IPBES Regional Assessments (Americas) and being co-Chapter Lead Author for the Sustainable Use of Wild Species Assessment, being an author on both IPCC Assessment Report V and the IPCC Special Report on the Ocean and Cryosphere, a core member of the Group of Experts for the World Ocean Assessment I (coordinator of Part VI on Biodiversity and Co-coordinator for Part IV on Fisheries), co-chapter lead for the Oceans and Coasts chapter of UNEP Global Environmental Assessment V.
} 
- A wide range of measures have been promoted if not as "silver bullets" at least as silver-plated solutions for unsustainability across a wide range of types of uses and circumstances (e.g., allocation of secure property rights; development of networks of protected areas, devolution of management to local scale processes; consolidation of decision-making in a central agency with mature processes for MCS² (Young et al., 2018; Martin et al., 2020).

- Eventually these silver-plated solutions tarnish, as circumstances arise where the measures do not reduce existing unsustainability of uses or else they amplify unsustainability elsewhere, and/or the sustainability that they initially delivered begins to unravel, as pressures on the resource(s) or socio-economic processes compound faster than the governance processes can reign them in.

These assessments have found many causes that can contribute singly or in combination to the pervasiveness of unsustainability of uses of Nature, and for unsustainable practices to resurrect, even when those managing and participating in the use(s) think unsustainability has been overcome.

\section{ROOTS OF UNSUSTAINABILITY}

Candidate drivers toward the pervasiveness of unsustainability include:

- Uncertainties in the assessments and other knowledge sources used to inform decision-making, so advice cannot be accurate and precise enough to guide reliable decisions (Punt et al., 2012; Farcas and Rossberg, 2016).

- Non-stationarity of environmental conditions and/or population and ecosystem dynamics, so information from the past is an incomplete and only partially reliable guide to actions in the future, and increasingly unreliable as projections extend further into the future (Bastardie et al., 2017; Koons et al., 2017).

- Insufficient resources and/or legitimate authority for effective MCS, whether from the top down or from the bottom up, so compliance with management decisions is insufficient to deliver the intended outcomes (Quimby and Levine, 2018; Troumbis and Hatziantoniou, 2018; Giglio et al., 2019).

- Either insufficient risk aversion in decision-making, so outcomes are not robust to inherent variability in environmental, economic and social factors that influence the sustainability, or excessive risk aversion that necessarily incurs very high opportunity costs and perhaps incentivizes non-compliance when resources appear to be unused, while people are in need (Holm, 2019; Ono et al., 2019; Hansson, 2020).

Other drivers could be added to this list, and some of the ones listed may be decomposed into smaller, possibly more tractable, sub-groupings. However, a complete list of potential drivers

${ }^{2}$ MCS is Management, Control, and Surveillance. to unsustainability isn't necessary, particularly when many of the factors presented as drivers toward unsustainability can be effective as drivers toward sustainability, if they are matched with policies and management tools effectively mixing incentives and deterrents. What matters is that:

- Substantial progress on each factor is possible when a proper diagnosis of the particular drivers underlying trends toward unsustainability is followed by implementation of appropriate measure(s) for the features of Nature being used or impacted, the manner of use, and the socio-economic context in which the use is occurring (Wright et al., 2020).

- Regardless of how much progress is made, unsustainability seems always "just around the corner" when either the factors previously responsible for unsustainable use reemerge in ways that may diminish or negate the measures used to tame the factor or in places where the tools are not readily applied, or new circumstances are encountered to which the existing management regime is not robust (Cochrane, 2020).

This pervasiveness of unsustainability could be surprising, because resource users rarely have "degradation of the part(s) of Nature being used" as an objective. Multiple communities may have different goals for how and how much to use shared resources, but they are at least likely to share the objective that they do not want it degraded to the point where uses, particularly their own, are not possible (Bellangier et al., 2020; Gaebel et al., 2020). There may be economic strategies and accounting approaches where "cashing out" a resource and investing the profits is a rational strategy, but even in those cases, reaching that decision and keeping the economic strategy viable requires a vision of "sustainability" shared by all those affected by that choice (Clark, 1973; Defrancesco et al., 2014). Irrational choices also may be made by participants in harvesting, without the intent of causing unsustainable outcomes (Battista et al., 2018), or management may be ineffective is delivering the desired outcomes (Garcia et al., 2014) but those realities merely underscore the messages in this essay. People have to be working together to achieve sustainable outcomes, and willing cooperation requires all those working together to perceive that they are being treated equitably.

And that is where experience in diverse assessment and advisory processes has led me to ask a simple but sweeping question. Why is unsustainability in uses of Nature so pervasive, when it is the one outcome all users want to avoid and when solutions to the individual contributing factors are known and have been successful (at least temporarily) on diverse scales and types of uses?

A cynic might focus on the multiplicity of users of most parts of Nature, so blame can always be transferred when things go bad, and no group takes accountability for its share of the problem. There is support for such a cynic's view, both from small scales, and in more multi-user settings from the investments made in processes to build shared objectives for cooperative resource use (Costanza et al., 2017; 
Alexander et al., 2018; Gelcich et al., 2019; Bellangier et al., 2020). However, the integrity of small, self-governing communities with a common shared culture is a weak precedent for sustainability of a diverse but globalized world. Moreover, these and other references illustrate that cooperative objectivesetting initiatives become increasing difficult, and produce consensus at progressively more abstract and less operational levels, as the intensity and number of resource users both increase. Similarly, some strategies seek sustainability by restricting access to resources sufficiently that macro-economic instruments can incentivize sustainable behaviors of those with access rights. These strategies narrowly improve sustainability of use of the resources, but often leave individuals or communities denied access facing reduced social and economic opportunity and potentially making important dimensions of sustainability worse, not better (e.g., Robards and Alessa, 2004; Van Dolah et al., 2020).

An optimist might say that failures to achieve or maintain sustainability in the past does not guarantee unsustainability will remain inescapable in the future. Knowledge keeps growing (particularly as a diversity of knowledge systems are used), capacity and tools to manage keep growing, and lessons from both successes (whether temporary or not) and new failures also keep growing (Cinner et al., 2019, 2020; Caswell et al., 2020; Hilborn et al., 2020). We all have to share some of this optimism, if we continue to be engaged in these assessment and related activities, work as experts in our areas of specialization, and read papers in volumes such as this one.

\section{IS THERE A WAY OFF THE UNSUSTAINABILITY TREADMILL?}

It is now common to say incremental change is not adequate to address the challenges of today's globalized world. "Transformational change" sounds great, is inclusive in scope and ambition (Abson et al., 2017; Horcea-Milcu et al., 2019), and vaguely enough delineated that people with diverse views, values and vulnerabilities can all endorse it, even while planning to do very different things under its umbrella (e.g., a Green or a Blue economy; devolution of decision-making paired with local empowerment and capacity-building). The list of transformational change components in the IPBES website ${ }^{3}$ is enlightening:

1. Go carbon-neutral, and expect others and businesses to do the same

2. Work to make it easy, enjoyable, and inexpensive to go Earth-positive.

3. Make all subsidies and incentives work for - not against the necessary transformations.

4. Make all decision-making precautionary, adaptive, inclusive and integrative across sectors and jurisdiction

5. Strengthen environmental laws and policies, and ensure their consistent enforcement - at home and abroad.

\footnotetext{
${ }^{3}$ https://ipbes.net/news/what-transformative-change-how-do-we-achieve-it
}

Every one of these things is worthwhile. Every one also has been tried many times, with track records of some progress, some setbacks, and outcomes that may eliminate an unsustainable practice for a while, but often end up mostly changing the nature of unsustainability, and/or where it is occurring. The very comprehensiveness of these "transformational changes" are part of their difficulty. The pathways by which each one of these components can be approached will look very different to the diverse perspectives (Heck et al., 2018; Horcea-Milcu et al., 2019; Rice et al., 2020). Making goals transformative rather than incremental does not in itself weaken the "blame game" among users sharing an over-used resource, nor make consensus easier to find when a broad conceptual goal has to be translated down to binding and restrictive limits on each Party (Jara-Guerrero et al., 2019).

Return to that core question "Why is unsustainability in uses of Nature so pervasive and nearly inescapable, when it is the one outcome all users want to avoid and when solutions to the individual contributing factors are known and have been successful on many different scales and types of uses?" After struggling with trying to find a viable answer through my long career of seeking sustainability, mostly within marine fisheries, I have concluded that there must be an underlying barrier that must be identified and dealt with effectively. Only then can we break this pattern and see real change - whether transformative or otherwise. Even though the evidence is incomplete, across all the cultural diversity of Humankind, that underlying and pervasive barrier is inequity in access to or the distribution of the wealth created by the benefits arising from our uses of Nature. I explain this perspective using primarily fisheries examples, but working within the global assessment frameworks has shown very comparable importance of addressing equity in uses of terrestrial resources as well, such as harvesting wild rice (Matson et al., 2019) and honey (Matias et al., 2018).

A few caveats on that statement. "Wealth" is not necessary measured in a currency exchanged commercially. It can be social capital or any factor that maintains or enhances one's place in one's society (Pascual et al., 2017; Ellis et al., 2019). By "inequity" I am not referring to a bland homogeneity of well-being, where every individual gets reward and constraints exactly equivalent to every other individual. Rather, cultural diversity is maintained only by respecting the diversity of values that different cultures may attach to the same parts of Nature; even within each society individual diversity ("taste") may differ in ways that can strengthen a community. I am using equity in the context of genuine social justice: equal access to and power within the processes that make decisions about how Nature's Contributions to People are accessed and distributed (Agyeman et al., 2016; Quimby and Levine, 2018).

Why is inequity in the access to and distribution of wealth created through uses of Nature a (possibly the) underlying cause of unsustainability uses of Nature? The reason is increasing inequity in the distribution of benefits necessarily increases pressures toward unsustainability from both the "winners" and "losers" in the inequity.

The few that accumulate an increasing proportion of the wealth sometimes come to make accumulating even more 
wealth be the goal of their operations. Individually that may be expressed as greed, and does not have to be universal. If even a minority of the "winners" in the distribution of wealth have the "Johnny Rocco Syndrome" ${ }^{4}$ " then it will drive the use to make creation of additional wealth for sake of having more wealth a priority (Soliman, 2014; Melnychuk et al., 2016). The successful minority can use this wealth as they wish. Uses may include redistributing some wealth "equitability" within their own value systems, but often includes using disproportionate wealth to have disproportionate influence over the decision-making processes. There are many commercial initiatives to adopt more socially responsible business practices (Cashore, 2002; Zucchella and Urban, 2014; Packer et al., 2019). Nevertheless, these, too, focus on using the wealth created through commerce responsibly, whereas intentionally limiting the amount of corporate wealth created is rarely considered "sound business practice." And the corporate world, like individuals, can use disproportionate wealth to influence decision-making processes in ways intended to minimally not threaten the means that they have used to accumulate their wealth (Osterblom et al., 2017).

Whether by individuals or corporations, gaining disproportionate wealth thus drives unsustainability both through potential for pursuing objectives of increasing wealth for its own sake, and through creating incentives to use wealth as power to influence the decision - making processes to not threaten their sources of wealth, and ensure any negative consequences of the increasingly concentrated wealth do not also fall disproportionately on those controlling the wealth. If this comes at the cost of families or whole communities displaced to urban ghettos or joining waves of migrants to the more affluent parts of the world, the unsustainability of these consequences may be easy to dissociate from the inequities behind decisions that actually cause it (Faist, 2018).

On the other end of the distribution spectrum are those receiving disproportionately little of the wealth created by uses of Nature. The concentration of wealth leaves an increasingly large proportion of the members of a community or society disadvantaged materially. This, in turn, leaves them both in greatest need of benefiting from further uses of Nature, and with the fewest options feasible for meeting their needs with sustainable choices (Leao et al., 2017). This is particularly the case if the paths to sustainability require greater costs or a slower rate of acquisition of benefits; neither of which is feasible for those in poverty. Moreover being marginalized economically within a community is likely to be accompanied by being disadvantaged in access to and exercise of power in decisionmaking (Vasseur et al., 2017; Trisos et al., 2019). These social and economic consequences of marginalization may become invisible if those most effected become migrants, but that just requires the boundaries in which evaluations of sustainability of outcomes to be redefined to continue to include all the livelihoods affected by the decisions.

So from both the few that become wealthy and the many that are left poor, inequity in the access to and distribution of

\footnotetext{
${ }^{4}$ Named for the gangster in the movie Key Largo, who when asked "What DO you want" simply answered "More! I want MORE!"
}

wealth from uses of Nature is likely to result in pressure to increase the intensity of the uses or maintain the intensity of use when it is excessive. This is accompanied by both the hope by those controlling much of the wealth that they can be shielded from consequences of any resultant unsustainability of the uses, and the desperation of those disadvantaged, who knowingly or unknowingly accept the consequences of unsustainability as necessary if they are to alleviate their poverty. When efforts to rectify historical inequities are added to the challenge, the entire process can be stressed, as is happening with Canada's Reconciliation efforts with its First Nations Peoples.

\section{DISCUSSION AND IMPLICATIONS}

The possibility to diagnose the underlying cause of the pervasiveness and persistence of unsustainable uses of Nature should be encouraging, because a correct diagnosis can help target more effective efforts at solutions. Unfortunately inequity in the distribution of wealth and access to decision-making power is a problem that has been part of human civilization for recorded history. There is ample recognition across societies and nations that extreme inequity is unjust, and governance processes from local to global have adopted Principles and processes intended to address inequity (Agyeman et al., 2016; Burgass et al., 2020). Correspondingly progress in fighting poverty and marginalization is being made (Cochrane, 2020). Nevertheless progress is slow and unequal at all scales, with even negotiated modest sustainable development goals rarely achieved and progress usually far short of more aspirational goals (Racioppi et al., 2020; Huan et al., 2021).

Even if the solutions to inequity will require actions on Policy levels far broader than just approaches to uses of Nature, constructive efforts to try to improve equity have been tried in all uses of living resources. These effort can work, but even in working, may just push the drive to excessive and unsustainable use to a deeper level. I will illustrate this with fisheries, which I know well. Particularly after WWII, with the expansion of international fisheries, TACs were set for commercial fisheries to cap at sustainable levels the amount of "wealth" that could be taken. Although TACs did restrict harvest levels, the pervasiveness of unsustainability led to the "race for fish," making fisheries more wasteful and less profitable, thereby actually generating less "wealth," and quota over-runs were common unless there was extensive surveillance and enforcement. In turn efforts were made to address the race for fish by allocating secure property rights to the fish harvesters. Again there were initial successes in advancing sustainability. However, rapidly those participants who were initially more successful in harvesting their allocation, or had better access to outside capital, began to acquire more quota shares, or otherwise to gain a disproportionate share of the total catch (Melnychuk et al., 2016). This resulted in fewer participants in the fishery; consequently more people or communities marginalized and needing to find livelihoods elsewhere, with significant social costs and again a concentration of decision-making power in the successful few. Again Policy could and often did respond by limiting the amount 
that fishing opportunities could be concentrated, but it is far too early to conclude that these measures are finally enough to ensure full equity in the distribution of benefits from fishing (Asche et al., 2018; Caswell et al., 2020). There is some reason for pessimism, in that at a minimum there is inherently an inequity between those who do and don't qualify to even have access to a quota share, and the governance and MCS processes that have had to be created and maintained to support setting accurate quotas, controlling access, and ensuring full compliance are complex and costly, often with costs recovered in full or in part by "resource rent" collected from the legal users (Flaaten et al., 2017; Gunnlaugsson et al., 2018). This makes the overall systems vulnerable to stochastic events such as environmental changes that would diminish stock productivity, require lower harvest and generate less revenue to support the governance and MCS systems just when their challenges have increased, and to politicization, as wealth and corresponding power is increasingly centralized in the interests of those who may benefit disproportionately from undermining constraints on their ability to increase their control over the processes.

This is not solely a pathology of large-scale uses of Nature. it is well documented that cultures of small and relatively selfsufficient communities developed social and cultural norms that promote equity in access to and distribution of benefits from Uses of Nature. However, these cultural norms and customs have social overhead and costs to maintain, and vulnerabilities to externalities that challenged the well-being of the communities (Cinner et al., 2019; Pihlajamaki et al., 2020). They also tended to be exclusionary - or at least not fully equitably - in how the norms and customs were applied to members and nonmembers of the communities (Barnes et al., 2016). Even looking at the important successes these norms and customs may have in promoting sustainability at the community level, these successes are increasing challenged as globalization increasingly influences cultures and practices at every scale (Giron-Nava et al., 2019; Crona et al., 2020). For example in many places the portion of community-based catches and takes from hunting and fishing that enters trade has grown substantially, as the fish and game are

\section{REFERENCES}

Abson, D. J., Fischer, J., Leventon, J., Newig, J., Schomerus, T., Vilsmeier, U., et al. (2017). Leverage points for sustainability transformation. Ambio 46, 30-39.

Agyeman, J. A., Schlosberg, D., Craven, 1, and Matthews, C. (2016). Trends and directions in environmental justice: from inequity to everyday life, community, and just sustainabilities. Annu. Rev. Environ. Resour. 41, 321-340. doi: 10.1146/ annurev-environ-110615-090052

Alexander, S. M., Epstein, G., Bodin, O., Armitage, D., and Campbell, D. (2018). Participation in planning and social networks increase social monitoring in community-based conservation. Conserv. Lett. 11:e12562. doi: 10.1111/conl. 12562

Asche, F., Garlock, T. M., Anderson, J. L., Bush, S. R., Smith, M. D., Anderson, C. M., et al. (2018). Three pillars of sustainability in fisheries. Proc. Natl. Acad. Sci. U.S.A. 115, 11221-11225.

Barnes, M. L., Lynham, J., Kalberg, K., and Leung, P.-S. (2016). Social networks and environmental outcomes. Proc. Natl. Acad. Sci. U.S.A. 113, 6466-6471.

Bastardie, F., Nielsen, J. R., Eero, M., Fuga, F., and Rinsdorf, A. (2017). Effects of changes in stock productivity and mixing on sustainable fishing and economic viability. ICES J. Mar. Sci. 74, 535-551. doi: 10.1093/icesjms/fsw083 targeted at urban food markets where families from rural areas have relocated seeking employment and opportunities. We are only beginning to understand how these changes are affecting sustainability of uses of Nature by these local communities, but I suspect many of the dynamics driving uses to unsustainability will be encountered, as "wealth" is increasingly influenced by market forces and product chains rather that community-scale well-being and social equity.

\section{Overall Conclusion}

Some voices are now calling for all human uses of wild species to be rethought, as society increases acknowledges animals, at least, are to some degree sentient and have some rights. The argument is that by treating Nature with greater Humanity, we will have a better foundation for interacting with Nature in ways that are sustainable. This may or may not be true, but it is a level of action far deeper than necessary to make the changes needed to promote sustainability. Equity is fundamental for People and cultures to be treating each other with Humanity. Simply fulfilling the many global commitments for People to treat each other with respect and justice will open up many possible pathways to use Nature sustainability. Failure to deal with inequity among people at every scale will ensure there remain few or no pathways that can attain and keep our uses of Nature sustainable.

\section{DATA AVAILABILITY STATEMENT}

The original contributions presented in the study are included in the article/supplementary material, further inquiries can be directed to the corresponding author.

\section{AUTHOR CONTRIBUTIONS}

I have done all research, thinking and drafting of this manuscript, benefiting from four decades of collaborations with diverse colleagues globally.

Battista, W., Romero-Canyas, R., Smith, S. L., Fraire, J., Effron, M., Larson-Konar, D., et al. (2018). Behavior change interventions to reduce illegal fishing. Front. Mar. Sci. 5:403.

Bellangier, M., Speir, C., Blanchard, F., Brooks, K., Butler, J. R. A., Crosson, S., et al. (2020). Addressing marine and coastal governance conflicts at the interface of multiple sectors and jurisdiction. Front. Mar. Sci. 7: 544440 .

Burgass, M. J., Larrosa, C., Tittensor, D. P., Arlidge, W. N. S., Caceres, H., Camaclang, A., et al. (2020). Three Key considerations for biodiversity conservation in multilateral agreements. Conserv. Lett. e12764. doi: 10.1111/ conl.12764

Cashore, B. (2002). Legitimacy and the privatization of environmental governance: how non-state market-driven (NSMD) governance systems gain rule-making authority. Governance 15, 503-529. doi: 10.1111/1468-0491.00199

Caswell, B. A., Klein, E. S., Alleway, H. K., Ball, J. E., Botero, J., Cardinale, M., et al. (2020). Something old, something new: Historical perspectives provide lessons for blue growth agendas. Fish Fish. 21, 797-812.

Cinner, J. E., Lau, J. D., Bauman, A. G., Feary, D. A., Januchowski-Hartley, F. A., Rojas, C. A., et al. (2019). Sixteen years of social and ecological dynamics reveal challenges and opportunities for adaptive management in sustaining the 
commons. Proc. Natl. Acad. Sci. U.S.A. 116, 26474-26483. doi: 10.1073/pnas. 1914812116

Cinner, J. E., Zamborain-Mason, J., Gurney, G., Graham, N. A. J., MacNeil, N. A., Hoey, A. S., et al. (2020). Meeting fisheries, ecosystem function, and biodiversity goals in a human-dominated world. Science 366, 306-310.

Clark, C. (1973). Profit maximization and the extinction of animal species. J. Political Econ. 81, 950-961. doi: 10.1086/260090

Cochrane, K. (2020). Reconciling sustainability, economic efficiency and equity in marine fisheries: Has there been progress in the last 20 years? Fish Fish. 20, 1-26.

Costanza, R., de Groot, R., Braat, L., Kubiszewski, I., Fioramonti, L., Sutton, P., et al. (2017). Twenty years of ecosystem services: how far have we come and how far do we still need to go? Ecosyst. Serv. 28(Pt A), 1-16.

Crona, B. I., Pomeroy, R. S., and Purcell, S. W. (2020). Editorial: small-scale and artisanal fisheries: insights and approaches for improved governance and management in a globalized context. Front. Mar. Sci. 7:455.

Defrancesco, E., Gatto, P., and Rosato, P. (2014). A 'component-based' approach to discounting for natural resource damage assessment. Ecol. Econ. 99, 1-9. doi: 10.1016/j.ecolecon.2013.12.017

Ellis, E. C., Pascual, U., and Mertz, O. (2019). Ecosystem services and nature's contribution to people: negotiating diverse values and trade-offs in land systems. Curr. Opin. Environ. Sustain. 38, 86-94. doi: 10.1016/j.cosust.2019. 05.001

Faist, T. (2018). The socio-natural question: how climate change adds to social inequalities. J. Intercult. Stud. 39, 195-206. doi: 10.1080/07256868.2018. 1446670

Farcas, A., and Rossberg, A. G. (2016). Maximum sustainable yield from interacting fish stocks in an uncertain world: two policy choices and underlying trade-offs. ICES J. Mar. Sci. 73, 10-21.

Flaaten, O., Heen, K., and Matthiasson, T. (2017). Profit and resource rent in fisheries. Mar. Resour. Econ. 32, 311-328. doi: 10.1086/692074

Gaebel, C., Baulcomb, C., Johnson, D. E., and Roberts, J. M. (2020). Recognising stakeholder conflict and encouraging consensus of 'science-based management' approaches for marine biodiversity beyond national jurisdiction (BBNJ). Front. Mar. Sci. 7:557546.

Garcia, S. M., Rice, J. C., and Charles, A. T. (eds). (2014). Governance for Marine Fisheries and Biodiversity Conservation: Interaction and Coevolution. Hoboken, NJ: Wiley InterScience.

Gelcich, S. J., Martinez-Harms, M., Tapia-Lewin, S., Vasquez-Lavin, F., and RuanoChamorro, C. (2019). Comanagement of small-scale fisheries and ecosystem services. Conserv. Lett. 12:e12637.

Giglio, V. J., Moura, R. L., Gibran, F. Z., Rossi, L. C., Banzato, B. M., Corsso, J. T., et al. (2019). Do managers and stakeholders have congruent perceptions on marine protected area management effectiveness? Ocean Coastal Manage. 179:104865. doi: 10.1016/j.ocecoaman.2019.104865

Giron-Nava, A. M., Johnson, A. F., Cisneros-Montemayor, A. M., and AburtoOropez, O. (2019). Managing at maximum sustainable yield does not ensure economic well-being for artisanal fishers. Fish Fish. 20, 214-223. doi: 10.1111/ faf. 12332

Gunnlaugsson, S. B., Kristofersson, D., and Agnarsson, S. (2018). Fishing for a fee: Resource rent taxation in Iceland's fisheries. Ocean Coastal Manage. 163, 141-150. doi: 10.1016/j.ocecoaman.2018.06.001

Hansson, S. O. (2020). How extreme is the precautionary principle? Nanoetics 14, 245-257. doi: 10.1007/s11569-020-00373-5

Heck, V., Hoff, H., Wirsenius, S., Meyer, C., and Kreft, H. (2018). Land use options for staying within the planetary boundaries - synergies and tradeoffs between global and local sustainability goals. Glob. Environ. Change Hum. Policy Dimensions 49, 73-84. doi: 10.1016/j.gloenvcha.2018.02.004

Hilborn, R. (2019). Measuring fisheries performance using the Goldilocks plot. ICES J. Mar. Sci. 116, 45-49. doi: 10.1093/icesjms/fsy138

Hilborn, R., Amoroso, R. O., Anderson, C. M., Baum, J. K., Branch, T. A., Costello, C., et al. (2020). Effective fisheries management instrumental in improving fish stock status. ICES J. Mar. Sci. 117, 2218-2224.

Holm, S. (2019). Precaution, threshold risk and public deliberation. Bioethics 33, 254-260. doi: 10.1111/bioe.12488

Horcea-Milcu, A.-I., Abson, D. J., Apetrei, C. I., Duse, I. A., Freeth, R., Riechers, M., et al. (2019). Values in transformational sustainability science: four perspectives for change. Sustain. Sci. 14, 1425-1437. doi: 10.1007/s11625-01900656- 1
Huan, Y., Liang, T., Li, H., and Zhang, C. (2021). A systematic method for assessing progress of achieving sustainable development goals: a case study of 15 countries. Sci. Total Environ. 752:141875. doi: 10.1016/j.scitotenv.2020.141875

Jara-Guerrero, A. K., Maldonado-Riofrio, D. E., Carlos, I., and Duncan, D. H. (2019). Beyond the blame game: a restoration pathway reconciles ecologists' and local leaders' divergent models of seasonally dry tropical forest degradation. Ecol. Soc. 24:22. doi: 10.5751/ES-11142-240422/

Koons, D. N., Arnold, T. W., and Schaub, M. (2017). Understanding the demographic drivers of realized population growth rate. Ecol. Applic. 27, 21022115. doi: 10.1002/eap.1594

Leao, T. C. C., Lobo, D., and Scotson, L. (2017). Economic and biological conditions influence the sustainability of hrvest of wild animals and plants in developing countries. Ecol. Econ. 140, 14-21. doi: 10.1016/j.ecolecon.2017. 04.030

Martin, E. J. G., Giordano, R., Pagano, A., van der Keur, P., and Costa, M. M. (2020). Using a system thinking approach to assess the contribution of nature based solutions to sustainable development goals. Sci. Total Environ. 738:139693. doi: $10.1016 /$ j.scitotenv. 2020.139693

Matias, D. M. S., Tambo, J. A., Stellmacher, T., Borgermeister, C., and von Wehrden, H. (2018). Analysis of honey from giant honey bees in Palawan, Philippines. Forest Policy Econ. 97, 223-231. doi: 10.1016/j.forpol.2018. 10.009

Matson, L., Ng, G. H. C., Dockery, M., Nyblade, M., King, H. J., Bellcourt, M., et al. (2019). Transforming research and relationships through collaborative tribal-university partnerships on Manoomin (wild rice). Environ. Sci. Policy 115, 108-115. doi: 10.1016/j.envsci.2020.10.010

Melnychuk, M. C., Essington, T. E., Branch, T. A., Heppell, S. S., Jensen, O. P., Link, J. S., et al. (2016). Which design elements of individual quota fisheries help to achieve management objectives? Fish Fish. 17, 126-142. doi: 10.1111/faf.12094

Ono, K., Langangen, O., and Stenseth, N. C. (2019). Improving risk assessments in conservation ecology. Nat. Commun. 10:2836.

Osterblom, H., Jouffray, J.-B., Folke, C., and Rockström, J. (2017). Emergence of a global science-business initiative for ocean stewardship. Proc. Natl. Acad. Sci. U.S.A. 114, 9038-9043. doi: 10.1073/pnas.1704453114

Packer, H., Swartz, W., Ota, Y., and Bailey, M. (2019). Corporate Social Responsibility (CSR) practices of the largest seafood suppliers in the wild capture fisheries sector: from vision to action. Sustainability 11:2254. doi: $10.3390 /$ sul1082254

Pascual, U., Balvanera, P., Diaz, S., Pataki, G., Roth, E., Stenseke, M., et al. (2017). Valuing nature's contributions to people: the IPBES approach. Curr. Opin. Environ. Sustain. 26-27, 7-16.

Pihlajamaki, M., Helle, I., Haapasaari, P., Sarkki, S., Kuikka, S., and Lehikoinen, A. (2020). Catching the future: applying Bayesian belief networks to exploratory scenario storylines to assess long-term changes in Baltic herring (Clupea harengus membras, Clupeidae) and salmon (Salmo salar, Salmonidae) fisheries. Fish Fish. 21, 223-236.

Punt, A. E., Siddeek, M. S. M., Garber-Yonts, B., Dalton, M., Rugolo, L., Stram, D., et al. (2012). Evaluating the impact of buffers to account for scientific uncertainty when setting TACs: application to red king crab in Bristol Bay, Alaska. ICES J. Mar. Sci. 69, 624-634. doi: 10.1093/icesjms/fss047

Quimby, B., and Levine, A. (2018). Participation, power, and equity: examining three key social dimensions of fisheries comanagement. Sustainability 10:3324. doi: 10.3390/su10093324

Racioppi, F., Martuzzi, M., Matic, S., Braubach, M., Morris, G., Krzyżanowski, M., et al. (2020). Reaching the sustainable development goals through healthy environments: are we on track? Eur. J. Public Health 30, 14-18. doi: 10.13189/ 1ls. 2020.080103

Rice, W. S., Sowman, M. R., and Bavinck, M. (2020). Using theory of change to improve post-2020 conservation: a proposed framework and recommendations for use. Conserv. Sci. Pract. 2:e301.

Robards, M., and Alessa, L. (2004). Timescapes of community resilience and vulnerability in the circumpolar north. Arctic 57, 415-427.

Soliman, A. (2014). Individual transferable quotas in world fisheries: addressing legal and rights-based issues. Ocean Coastal Manage. 87, 102-113. doi: 10.1016/ j.ocecoaman.2013.09.012

Trisos, C. H., Alexander, S. M., Gephart, J. A., Gurung, R., McIntyre, P. B., and Short, R. E. (2019). Mosquito net fishing exemplifies conflict among sustainable development goals. Nat. Sustain. 2, 7-9. 
Troumbis, A. Y., and Hatziantoniou, M. N. (2018). Too much, too fast, too complex or too strange? Asymmetric sequences in public opinion regarding biodiversity conservation in Island social-ecological setups. Biodivers. Conserv. 27, 1403-1418. doi: 10.1007/s10531-018-14 99-9

Van Dolah, E. R., Miller Hesed, C. D., and Paolisso, M. J. (2020). Marsh migration, climate change, and coastal resilience: human dimensions considerations for a fair path forward. Wetlands 40, 1751-1764. doi: 10.1007/s13157-020-01 388-0

Vasseur, L., Horning, D., Thornbush, M., Cohen-Shacham, E., Andrade, A., Barrow, E., et al. (2017). Complex problems and unchallenged solutions: bringing ecosystem governance to the forefront of the UN sustainable development goals. Ambio 46, 731-742. doi: 10.1007/s13280-017-0918-6

Wright, A. D., Bernard, R. F., and Mosher, B. A. (2020). Moving from decision to action in conservation science. Biol. Conserv. 249:108698. doi: 10.1016/j. biocon.2020.108698

Young, O. R., Webster, D. G., Cox, M. E., Raakjær, J., Blaxekjær, L. Ø, Einarsson, N., et al. (2018). Moving beyond panaceas in fisheries governance.
Proc. Natl. Acad. Sci. U.S.A. 115, 9065-9073. doi: 10.1073/pnas.171654 5115

Zucchella, A., and Urban, S. (2014). Futures of the sustainable firm: an evolutionary perspective. Futures 63, 86-100. doi: 10.1016/j.futures.2014.08.003

Conflict of Interest: The author declares that the research was conducted in the absence of any commercial or financial relationships that could be construed as a potential conflict of interest.

The reviewer RH declared a past co-authorship with the author to the handling editor.

Copyright (c) 2021 Rice. This is an open-access article distributed under the terms of the Creative Commons Attribution License (CC BY). The use, distribution or reproduction in other forums is permitted, provided the original author(s) and the copyright owner(s) are credited and that the original publication in this journal is cited, in accordance with accepted academic practice. No use, distribution or reproduction is permitted which does not comply with these terms. 